\title{
Erratum to: Mineral resources in life cycle impact assessment-defining the path forward
}

\author{
Johannes A. Drielsma ${ }^{1}$ - Andrea J. Russell-Vaccari ${ }^{2} \cdot$ Thomas Drnek $^{3} \cdot$ Tom Brady $^{4}$. \\ Pär Weihed $^{5} \cdot$ Mark Mistry $^{6} \cdot$ Laia Perez Simbor $^{7}$
}

Published online: 26 November 2015

(C) Springer-Verlag Berlin Heidelberg 2015

Erratum to: International Journal of Life Cylce Assessment DOI 10.1007/s11367-015-0991-7

The name of the author Johannes A. Drielsma was rendered wrongly in the original publication but has since been corrected. The publisher apologizes for this error and the inconvenience caused.

The online version of the original article can be found at http://dx.doi.org/ 10.1007/s11367-015-0991-7.

\footnotetext{
Andrea J. Russell-Vaccari
}

andrea@alignconsultants.com

1 European Association of Mining Industries, Metal Ores and Industrial Minerals, Avenue de Broqueville/Broquevillelaan 12, 1150 Brussels, Belgium

2 Align Consulting, 1134 Cross Creek Ct, Sheridan, WY, USA

3 RHI AG, Magnesitstrasse 30, 8614 Breitenau, Austria

4 Newmont Mining, 6363 South Fiddler's Green Circle Suite 800, Greenwich Village, CO 80111, USA

5 Lulea Technical University, Luleå 97187, Sweden

6 The Nickel Institute, Avenue des Arts/Kunstlaan, 13, 1210 Brussels, Belgium

7 European Copper Institute, Avenue de Tervueren/Tervurenlaan 168, b-10, 1150 Brussels, Belgium 